\title{
Deslocamentos transnacionais da soberania popular \\ Império e multidão como distinção pós-democrática?
}

Pablo Holmes

Introdução

Cresce no senso comum teórico das ciências sociais a impressão de que as semânticas tradicionais do sistema político moderno não são mais capazes de oferecer uma descrição adequada das estruturas contemporâneas desse sistema na sociedade mundial atual ${ }^{1}$. De um lado, seus conceitos básicos não parecem mais ser capazes de descrever os mecanismos de regulação e governo de uma ordem mundial que se tornou em grande parte heterárquica, na qual a noção de soberania nacional foi em grande medida relativizada. Por outro lado, surgem novos conflitos e formas de politização que não se deixam mais explicar completamente pelos velhos arranjos ideológicos que marcaram os séculos XIX e XX, ou tampouco pela semântica de conflitos de interesses do que tradicionalmente se denominou contentious politics (Tilly, 2004, pp. 4-10).

De fato, vários indícios sugerem uma mudança estrutural importante da política no século XXI. Desde a crise financeira mundial de 2008, acentuou-se a observação de que há uma crescente incapacidade dos sistemas políticos nacionais em dar respostas às demandas por legitimação de decisões coletivamente vinculantes. Decisões importantes tomadas ao redor do globo podem cada vez menos ser nitidamente atribuídas a autoridades nacionais ou a organizações internacionais legitimadas por mecanismos estatais, embora

1. Alguns falam de um giro cosmopolita das ciências sociais. Ver, por exemplo, Beck (2009, pp.7094) e Brunkhorst (2012, p. 173). 
2. Sobre a emergência de um "poder privado" de regulação no plano transnacional, ver Hall e Biersteker (2004, pp. 3-22). Sobre a relação entre esse fenômeno e o processo de desregulação política associado, normalmente, ao que se convenciona chamar neoliberalismo, ver Crouch (2011, pp. 1-24) suas consequências para o público, como coletividade, sejam extremamente relevantes e muitas vezes transcendam fronteiras territoriais (Crouch, 2004, p. 7). Tais transformações não apontam apenas para o significado crescente de estruturas e organizações inter ou supranacionais de governo, como a ONU, a OMC, a União Europeia etc., mas também para a emergência de ordens regulatórias transnacionais (Djelic e Sahlin-Andersson, 2006, pp. 1-30), muitas delas compostas e controladas por atores privados ${ }^{2}$ e dotadas de grau maior ou menor de informalidade (Nölke, 2011).

Enquanto cientistas políticos e sociais do chamado mainstream continuaram em grande medida interessados nas estruturas políticas existentes nos Estados, observando-as sob o pano de fundo teórico da semântica da política democrática nacional, alguns teóricos políticos, sociais e do direito tentaram operar de modo mais inventivo diante das transformações da política nas últimas décadas. Entre diversos autores que se ocuparam desses problemas, Michael Hardt e Antonio Negri propuseram a diferença teórica entre império e multidão como candidata conceitual a oferecer uma explicação para a nova constelação política pós-nacional. Ao seu modo, eles descrevem uma nova configuração política em que o Estado nacional não é mais o portador último da soberania. Esta seria então atribuída ao que chamam de império, uma ordem política global que se oporia a multidão, que lhes serve como portadora de anseios democratizantes (Hardt e Negri, 2001, pp. 1-66).

A proposta teórica dos autores parece ser tão criativa quanto problemática. Em parte por ignorar a fragmentação da sociedade mundial moderna, sobretudo no rastro do processo de transnacionalização, eles em grande medida simplificam seu diagnóstico por meio de distinções muitas vezes imprecisas. Neste artigo, procurarei observar sua formulação sob uma perspectiva sociológica. Para isso, utilizarei uma teoria dos sistemas para observar possíveis virtudes e problemas de sua construção teórica. Na primeira parte, reconstruirei a relação entre semântica e estrutura no interior do sistema político moderno, principalmente com referência ao conceito de soberania popular. Depois, esboçarei uma descrição do papel de organizações sociais de distintos sistemas no processo de transnacionalização da economia, do poder e do direito na sociedade mundial, os quais parecem pressionar o arranjo democrático constitucional do Estado nacional. Passarei a expor, então, o diagnóstico de Hardt e de Negri acerca da política mundial atual. E, na última parte, farei uma avaliação crítica da semântica política proposta pelos autores, segundo a hipótese de que ela pode significar mais um relevante sintoma da emergência de novas formas de governo na sociedade mundial. 
Na teoria dos sistemas, o conceito de "semântica" serve para indicar uma condensação e uma confirmação do sentido, dada por meio da sua repetição e sua estabilização na forma de expectativas dotadas de certa generalidade (Luhmann, 1997, p. 46). Para Niklas Luhmann, a "reprodução de sentido é garantida já pelas palavras da língua" (Idem, p. 47), que servem como meio desacoplado surgido evolutivamente para a fixação do sentido. Semânticas compostas por palavras são reais apenas por causa da ação social que as atualiza (Luhmann, 1980, p. 20). Como qualquer sistema social não passa de uma contínua repetição recursiva de eventos de sentido, não existe semântica sem que haja estruturas a tornar razoavelmente provável a manutenção da operatividade do sistema. A semântica é, por assim dizer, o resultado da razoável permanência de determinada estrutura social. E, por outro lado, se não houvesse açóes sociais, não haveria estruturas e, logo, qualquer semântica social.

Isso não quer dizer que a teoria social deva ser uma teoria da ação (Stichweh, 2000a, pp. 5-13). O agir e o vivenciar sociais são compreendidos por uma teoria dos sistemas como constelações de atribuição de sentido que servem à observação de operações comunicativas por meio de operações comunicativas (ou da observação de sentido no meio sentido). A depender de como uma ação social apareça para um observador, "podem variar os estímulos para a construção de sentido e, assim, para a construção de uma semântica que possa registrar, organizar e tornar acessível determinadas experiências sociais de sentido" (Luhmann, 1980, p. 22). A diferença entre operação e observação corresponde, na teoria dos sistemas, à existência de dois níveis de estruturas: um que se refere à estrutura de diferenciação (as possibilidades concretas de ação em uma sociedade) e outro que se refere às semânticas capazes de tornar o sentido identificável, fixando-o e possibilitando a sua lembrança ou esquecimento (Luhmann, 1997, p. 538).

Se um sistema social é complexo o suficiente para observar a si mesmo, descrevendo-se pela diferença entre si e o meio ambiente, ele se torna capaz de "refletir a sua própria unidade como ponto de referência para observações" (Idem, p. 880). Sistemas sociais que adquirem certa estabilidade, como é o caso do sistema político moderno, podem produzir para si, nesse nível abstrato de observação, quadros semânticos próprios, que servem à sua autodescrição. Por meio de textos, surgem autodescrições como artefatos semânticos que, na teoria dos sistemas, podem ser chamados de "semânticas elaboradas" (gepflegte Semantik) (Luhmann, 1980, p. 19): uma estrutura que ao mesmo tempo fun- 
ciona como descrição interna do sistema e como quadro semântico a delimitar "conceitualmente" sua operação (Stichweh, 2000, pp. 237-250).

Nesse ponto, é relevante lembrar um postulado teórico importante da teoria dos sistemas como uma teoria da diferença: nenhuma observação - e isso vale também para autodescrições, como formas particulares de observação - está em condições de observar a si mesma totalmente. Como toda observação tem lugar apenas em um ponto no presente (um evento), no qual se realiza uma distinção que designa um lado de uma diferença ao mesmo tempo que deixa o outro lado ignorado, ela pode observar a si mesma apenas posteriormente (no tempo). Assim, nenhuma operação pode observar o lado que deixou de designar, no momento que, operando, realizou uma distinção: este é seu ponto cego (blinder Fleck) (Luhmann, 1997, pp. 86-87). Em outras palavras, toda observação desloca as possibilidades de definição da própria unidade para observações posteriores, que por sua vez estão também condenadas à mesma limitação e à necessidade de realizar o mesmo tipo de deslocamento (Verschiebung) (Luhmann, 1997, pp. 54-59, 880 e ss.; 2004, pp. 244-250).

Dessa forma, um sistema pode observar a si próprio e produzir uma semântica autodescritiva. Essa auto-observação se torna, porém, uma estrutura social com duplo caráter: ela observa operações do sistema, a posteriori, e funciona como um artefato semântico que não pode se auto-observar senão a posteriori, além de também poder ser observado por outros sistemas (por exemplo, pelas ciências sociais, pela história, filologia, estudos culturais etc.). Autodescrições são, assim, (auto)representações deslocadas da própria unidade de um sistema social, que observam sua diferença em relação ao meio ambiente. Elas permanecem em alguma medida dependentes de observações de estruturas sociais preexistentes e, assim, semânticas de certa forma posteriores à estrutura social (basal) do sistema que observam (Luhmann, 1997, p. 883), embora possam apresentar um caráter constitutivo para novas formas sociais, na medida em que limitam as possibilidades de oscilação estrutural e têm a capacidade de ressignificar determinadas estruturas (Stäheli, 2000, pp. 218-223)

As "semânticas elaboradas" formam, por assim dizer, uma "história das ideias" interna a determinado sistema social, em relação direta com a evolução das suas "estruturas", seja porque funcionam como sua descrição interna, seja porque, em última análise, servem como artefatos semânticos úteis para seu funcionamento. No contexto do sistema político, pode-se perceber a existência dessa "história interna das ideias" em conceitos como "representação", "soberania," "Estado de direito", "constituição", "soberania popular" (Luhmann, 
2000, p. 319), os quais ao mesmo tempo servem à descrição do sistema, à sua operacionalidade e ao condicionamento de sua evolução.

Uma observação da semântica política moderna nos levaria, assim, à pergunta: "Como o sistema político comunica, internamente, sobre sua própria unidade?" (Idem, p. 319). Do ponto de vista estrutural, esse sistema poderia ser descrito como o resultado de: (a) um processo de especialização sistêmica em torno de uma função - a de manter a capacidade social de decidir coletivamente (Idem, pp. 81-88); (b) um processo de generalização da comunicação por meio do código poder. A sua diferenciação coincidiria com um processo de diferenciação do seu código. Para a teoria dos sistemas, também no caso da política, a observação da unidade do poder só pode ser compreendida a partir de uma diferença. A unidade do código poder seria, portanto, a unidade da diferença entre autoridade e submissão (Idem, pp. 29-36). "Mas como se pode designar a unidade dessa diferença no sistema ele próprio, já que qualquer operação desse sistema depende, desde sempre, de que essa diferença seja utilizada para observá-la, e sempre desde um lado dessa respectiva diferença?" (Idem, p. 322). Como conceber uma unidade para o sistema político que represente, ao mesmo tempo, autoridade e submissão, governo e oposição, ao mesmo tempo que essa unidade precisa ser observada por uma dessas perspectivas? Fatalmente, essa unidade teria de ser concebida apenas como um paradoxo, implicando enunciados como "a autoridade é submissa" ou "o dono do poder não tem poder algum". Esse fato refletiria, por fim, a instabilidade de toda forma de autoridade e a improbabilidade da diferenciação operativa do sistema político moderno.

Como em todos os sistemas sociais, o paradoxo que reside na própria forma do código poder precisa ser deslocado, ou invisibilizado, se o sistema político puder se manter operante. Isso se revela, inicialmente, no plano da reflexividade, que lida com o problema da identificação de qual pretensão de poder pertence ao sistema (e não é apenas proveniente de uma outra ordem concorrente), e no plano da reflexão, que diz respeito às descrições da unidade do sistema político (sua legitimidade, sua relação com outros sistemas etc.) $)^{3}$. Transformações semânticas, em ambos os níveis, tenderiam a refletir a incapacidade de determinada semântica em realizar essa invisibilização dos paradoxos operativos do sistema.

No caso do processo de diferenciação do sistema político moderno, a teoria dos sistemas reconstrói três formas de paradoxo que derivam da auto-observação interna da unidade do sistema (reflexão) e suas respectivas possibilidades de invisibilização (ou de deslocamento), dependendo de contextos distintos de reprodução operativa no nível estrutural (da operatividade basal
3. Para a diferença entre níveis de auto-observação, ver Luhmann (1987, pp. 615-625). 
4. Essa noção é generalizada por Carl Schmitt (1895, p. 11) na forma de uma ontologia política que define a soberania e, logo, o problema social da política, como o poder de decidir sobre o Estado de exceção. A partir de um ponto de vista sociológico seria mais produtivo observar se sociedades não podem apresentar formas diversas, semânticas e estruturais de lidar com o paradoxo do poder. Uma generalização apressada de uma única diferença como suficiente para descrever um sistema pode ser útil para finalidades dentro do sistema político, mas pode padecer de limitações conceituais e empíricas graves. e da reflexividade). Primeiramente, observam-se formas de invisibilização do paradoxo da unidade do sistema que correspondem a formas estruturais hierárquicas de diferenciação do poder, baseadas em estamentos, classes etc. $\mathrm{O}$ sistema tem, assim, que lidar com o paradoxo do todo e de suas partes, o qual consistiria no problema de que o todo (o sistema político) é formado por um conjunto de partes (as diferentes classes ou estamentos), mas ao mesmo tempo é entendido como algo mais do que a mera soma de seus elementos, já que esses elementos são desiguais entre si. Esse paradoxo é invisibilizado por meio do conceito de representação, que afirma que as partes se deixam representar, como unidade, por meio de uma delas (a classe superior governante) (Idem, pp. 324-334). Do ponto de vista simbólico, a metáfora dos dois corpos do rei parece servir como exemplo dessas estratégias operativas de invisibilização (Kantorowics, 1997).

O segundo paradoxo corresponderia às formas iniciais de diferenciação do poder, no contexto de sociedades com sistemas políticos extremamente centralizados, mas ainda baseados em formas hierárquicas de organização. Trata-se do problema da limitação da arbitrariedade, que conduz ao paradoxo de que a limitação do arbítrio exige sempre um arbítrio que a limite. Tal paradoxo teria se deixado invisibilizar por meio do conceito clássico de soberania, como um centro de poder que se fundamenta a si próprio, como aquele que decide quando e como pode decidir (Luhmann, 2000, pp. 334-349). ${ }^{4}$

Por fim, no contexto da gradual e improvável diferenciação do código poder, emergiu uma ordem política estruturada não mais por formas de estratificação (hierarquias), mas por uma regulação e um controle autorreferenciais da variação entre os polos dominação e submissão. Essa diferença foi então gradativamente temporalizada, na forma de oscilação entre governo e oposição, por meio de processos eleitorais e administrativos juridificados (Holmes, 2013, pp. 120-128; Walker, 2008, pp. 525-527; Lindahl, 2010). Esse processo, que pode ser associado ao processo de constitucionalização política e que implica uma diferenciação recíproca e um novo acoplamento entre direito e política, possibilitou um grau até então desconhecido de diferenciação para ambos os sistemas (Luhmann, 1990, pp. 201-208; Vesting, 2009, pp. 609-626). No que diz respeito ao direito, isso possibilitou que esse sistema se diferenciasse, especializando-se na função de estabilizar expectativas normativas (Luhmann, 1993, p. 124).

Certamente apenas em algumas regióes da sociedade mundial moderna verificou-se uma realização estável desse processo. Mas, onde ele se tornou possível, o sistema jurídico pôde contar com processos políticos processua- 
lizados e temporalizados que, em alguma medida, neutralizam conjunções particularistas (privadas) (Luhmann, 1993, pp. 407 e ss.), capazes de influenciar a reprodução do código lícito/ilícito. Assim, pôde-se ao menos produzir uma expectativa contrafática em relação à reprodução de hierarquias de poder que não fossem aquelas válidas de acordo com os próprios critérios internos do sistema jurídico, na forma de uma "comoditização privada do direito" (Pashukanis, 2002, pp. 109-134; Mieville, 2004, pp. 271-276 e 281). Do ponto de vista da política, isso quis dizer que a regulação entre os processos de inclusão e exclusão no sistema político assim como a regulação da oscilação entre governo e oposição passaram a ser um problema atinente apenas ao próprio sistema político, que, por seu turno, não poderia mais se apoiar em critérios hierárquicos para excluir indivíduos ou grupos de modo legítimo. Fala-se, assim, em democratização como a inclusão política de todos os possíveis cidadãos nos processos (Luhmann, 2000, p. 90).

A democracia, conceito que serve para descrever esse processo de diferenciação, exibe, contudo, uma forma paradoxal particular. Como se baseia também na diferença constituinte do código poder, ela precisa ser concebida como uma forma de dominação que se domina a si própria, ou de uma dominação dos dominados (Brunkhorst, 2002, p. 100). Evolutivamente, esse paradoxo foi invisibilizado por meio da semântica da soberania popular (Volkssouveränität), que invisibilizaria, no plano da reflexão, a instabilidade sobre a qual o sistema político democrático se funda (Luhmann, 2000, pp. 349-365; Kastner, 2007, pp. 92-95).

Evidentemente, esse processo de diferenciação política só se tornou possível graças a um amplo processo de centralização, favorecido pelo surgimento de organizações estatais que visibilizavam e estabilizavam a distribuição do código poder socialmente nos Estados europeus. O chamado Estado democrático de direito - que de fato permaneceu uma experiência de exceção sobretudo europeia na sociedade mundial (Neves, 1992) - representa uma superorganização que contém em seu interior diversos outros sistemas organizacionais, como um parlamento e órgãos administrativos, em que o poder político circula internamente como meio de comunicação (Luhmann, 1981, p. 47), ou como um sistema judiciário, em que o direito opera, de modo funcionalmente diferenciado, como segundo código do poder (Luhmann, 1993, p. 142). Essa era, pelo menos, a descrição do modelo que, bem ou mal, serviu ao processo de expansão da diferenciação funcional moderna. 
Transnacionalização da sociedade mundial e transformações da política

Nas últimas décadas parecem ter se tornado problemáticas algumas das premissas fundamentais da descrição hegemônica do processo de diferenciação funcional da política moderna. Isso se aplica especialmente à ideia de que decisões coletivamente vinculantes são tomadas, exclusivamente, no contexto de Estados constitucionais, que funcionam como o centro do sistema político.

De fato, de acordo com essa descrição, o Estado funcionaria como o critério último de uso do código poder em um determinado território. Se essa ilusão de onipotência foi verificada de modo apenas relativo e sobretudo limitado a poucas regiōes da sociedade mundial, hoje ela parece ter se tornado ainda mais improvável (Ruggie, 1998, pp. 79-98). Seja por conta da crescente concorrência entre Estados nacionais por uma posição privilegiada como ponto de atração de capitais e investimentos (Scharpf, 1997); seja por conta da crescente limitação interna ao poder regulador dos Estados diante de atores privados cada vez mais capazes de impor seus interesses (Crouch, 2011, pp. 71-96); seja ainda por causa da crescente complexidade social que muitas vezes suplanta a capacidade dos agentes políticos de produzir regulação adequada (Teubner, 1998, pp. 406-414, Grimm, 2001, pp. 489-506): os padrões descritivos do Estado como o único centro de decisóes com caráter coletivo se tornaram cada vez menos verificável.

Segundo Willke (2003), diversas transformações estruturais levaram a um crescente processo de transnacionalização da sociedade mundial nas últimas décadas. Transformações tecnológicas dos processos produtivos, a aceleração da velocidade dos meios de comunicação e dos meios de transporte, além de um conjunto de decisões que possibilitou a integração global de mercados, sistemas educacionais e científicos (Keohane, 2002, pp. 245-271), teriam levado a uma perda de importância da dimensão espacial da comunicação social em favor da dimensão temporal (Willke, 2003, pp.3-28). A consequência mais importante desse fenômeno, em termos sociológicos, teria sido o significado crescente de organizaçôes sociais ligadas aos sistemas funcionais, principalmente aquelas capazes de otimizar o uso do tempo e se adaptar a formas não espaciais de reprodução. Essas organizações passaram a poder se aproveitar de um verdadeiro "caos estruturado" - ou de certa "anarquia organizada" - presente na sociedade mundial, "para perseguir novas possibilidades de benefícios, em sua busca incessante por novas chances e riscos” (Idem, p. 82). Organizações não políticas são definidas como sistemas sociais extremamente flexíveis em termos espaciais. Elas podem se dividir, fundir, fragmentar, dissolver e estabelecer 
novamente, aproveitando o tempo como meio de ação e recurso, traduzindo diferenças espaciais cada vez mais em linguagem temporal. Elas conseguem, por exemplo, formar redes entre seus agentes e representantes que independem do espaço (Carrol e Fennema, 2002, pp. 393-419), ou travar acordos informais, articulando-se em redes, muitas vezes em detrimento dos interesses de outras organizações cujas operações permanecem espacialmente a um território, como é o caso do Estado.

Por outro lado, diante do processo cada vez mais acentuado de transnacionalização, organizações de diferentes sistemas funcionais (empresas, universidades, organizações esportivas, científicas e médicas) procuram estabelecer também seus próprios mecanismos de controle e estabilização de expectativas. Sobretudo por meio de contratos, elas podem fixar ordens de convivência que favorecem a previsibilidade de suas ações e eliminam incertezas (Teubner, 1996; Wiener, 1995). Assim, surgem crescentes conflitos entre ordens jurídicas constituídas a partir de um acoplamento estrutural com a política, cujos centros são organizações estatais, e ordens de regulação transnacionais, formuladas não a partir de interações com a política, mas a partir de imperativos funcionais de setores sociais específicos, como a economia de mercado, a ciência, a pedagogia, o esporte etc. (Willke, 2003, p. 83). Enquanto o direito do Estado é formulado com vistas à regulação contrafática da ação social (Holmes, 2013, pp. 89-96 e 108-120), permanecendo espacialmente delimitado (Lindahl, 2010, pp. 32-39), o direito das organizaçôes, constitucionalizado "funcionalmente" (Brunkhorst, 2012, pp. 253-275; Teubner, 2012, pp. 159168), estrutura-se a partir das necessidades de adaptação de organizações no espaço transnacional em que estas se movimentam (Amsturtz e Karavas, 2009, pp. 659-672). Além de serem atópicos (Willke, 2001, pp. 123-144) ${ }^{5}$, esses regimes de normas funcionais são extremamente flexíveis, orientando-se não por expectativas contrafáticas, de caráter normativo, mas por formas cognitivas e adaptativas que dispensam o uso da força para sua efetividade e se apoiam na força de imperativos funcionais (ao que se convencionou chamar soft law) (Sand, 2009, pp. 871-886). Isso faz com que o direito, no plano transnacional, viva um processo de diferenciação crescente em relação a esferas como a economia, a ciência e outros sistemas funcionais, algo que coloca definitivamente em xeque as estruturas políticas do Estado moderno e a forma "democrática" de reprodução do poder.
5. Para uma crítica do direito atópico como não direito ( $a$ -legality), ver Lindahl (2010, pp. 30-56). 
Império e multidão como diferença descritiva da política global

Nos últimos anos, foram propostas algumas alternativas teóricas para tentar descrever as relações políticas da sociedade mundial atual em sua nova conformação. Entre as propostas que se destacaram está a de Michael Hardt e Antonio Negri, que parece tentar reabrir as possibilidades de politização em um sistema político que cada vez mais parece se tornar alheio às formas tradicionais de conflito.

Se compreendo corretamente, com o conceito de império os autores tentaram trazer de volta ao debate teórico o conceito de soberania (Kalyvas, 2003, p. 265), levando em conta o fato de que, sob as condições atuais, esta não é mais exercida como uma forma de dominação territorial (Hardt e Negri, 2001, pp. 183-190; ver Goodale, 2005, p. 557). Como "soberano mundial”, o império não observaria quaisquer fronteiras espaciais, diferenças institucionais rígidas ou distinções étnicas; ele dominaria politicamente de modo atópico sobre todo o planeta como um regime total (Hardt e Negri, 2001, pp. XIV, $10 \mathrm{f}$ e 183-185). Isto é, sua soberania não seria exercida sobre um território ou uma população específica, mas sobre todas as formas de vidas mundiais (Idem, p. 14). O império é "o único sistema de autoridade que absorveu e eliminou o seu exterior em todas as suas manifestações e formas" (Kalyvas, 2003, p. 266). Sua lógica funciona de modo semelhante àquela do mercado global, cuja ideologia poderia ser pensada como expressão de formas de discurso antifundacionista e antiessencialista. "Circulação, mobilidade, diversidade e mistura" são "a própria condição de possibilidade" tanto do mercado como do império (Hardt e Negri, 2001, p. 150). Ambos superam quaisquer fronteiras, substituindo-as pela lógica ilimitada e flexível de mercados plurais, traduzindo toda a vida social na linguagem do "consumo de commodities", da "compra permanente" e das "imagens comodificadas" (Idem, p. 152).

Sob a soberania do império, encolhem os domínios liberais clássicos do público e do privado. "A paisagem urbana abandona o foco moderno na praça comum e no encontro público para se concentrar nos shopping centers, autoestradas e condomínios fechados" (Idem, p. 188). E mesmo as atividades que permanecem ligadas ao Estado passam a ser reguladas de acordo com a forma mercadoria do direito privado. Tampouco a vida privada permanece intocada. Hardt e Negri recordam que Foucault havia concebido a subjetividade moderna como consequência de uma série de instituiçóes capazes de incluir e excluir o indivíduo de diversos setores sociais: a escola, a família, a fábrica, a universidade, a prisão. Essas instituições operavam, porém, sempre 
baseadas na territorialidade, até mesmo porque elas necessitavam de limites espaciais, permanecendo ligadas, no mais das vezes, a Estados nacionais. Com a transição para a assim chamada "soberania imperial", essas instituições teriam sido desterritorializadas. "A produção da subjetividade na sociedade imperial tende a não mais se limitar a nenhum lugar específico. A pessoa está sempre, e ainda, na família, sempre, e ainda, na escola, sempre, e ainda, na prisão etc." (Idem, p. 197). O poder "é exercitado por meio de máquinas que organizam diretamente os cérebros (graças a meios de sistemas comunicação, redes de informação etc.)" (Idem, p. 25). O soberano imperial é um soberano biopolítico absoluto (Kalyvas, 2003, p. 266), que não deixa qualquer espaço para a privacidade.

Contudo, o encolhimento das formas políticas liberais não significa, para Hardt e Negri, que todas as esperanças em relação à democracia devam ser abandonadas. Em vez de acompanhar a tradição que insiste em uma crítica total da sociedade e de seus sistemas na linha da dialética do esclarecimento e de Michel Foucault (ver Brunkhorst, 2000, pp. 133-140; Honneth, 1989, pp. 195-225), que a ela se limita, os autores desenvolvem uma proposta teórica que aponta para a possibilidade de derrubada da ordem soberana imperial (Kalyvas, 2003, p. 266). Segundo eles, tal acontecimento não pode ser compreendido como um resultado necessário, senão como dependente da capacidade de resistência de uma multidão.

Com efeito, o império não poderia ser de modo algum compreendido sem referencia à multidão, já que esta representa para os autores a base de toda a lógica produtiva global. Hardt e Negri relacionam então as transformações profundas da dominação política e governo a transformações do modo de produção capitalista. Segundo eles, "nas décadas finais do século XX, o trabalho industrial perdeu sua hegemonia e em seu lugar emergiu o trabalho imaterial, quer dizer, o trabalho que fabrica produtos imateriais tais quais conhecimento, informação, comunicação, relações sociais ou respostas emocionais" (Hardt e Negri, 2004, p. 108). Na sociologia econômica e do trabalho, essas transformações, conceituadas como uma transição para uma ordem econômica pós-fordista (Jessop, 1995, pp. 307-333), indicariam o surgimento de uma economia baseada em formas produtivas móveis e flexíveis, como em uma crescente precarização do trabalho.

Hardt e Negri veem, porém, uma dimensão positiva das novas formas de trabalho. Para eles, uma característica fundamental do trabalho biopolítico (pós-fordista) consistiria em que seus produtos são em diversos sentidos imediatamente sociais e comuns (Hardt e Negri, 2004, pp. 289-294). Com isso, os autores procuram indicar que essa forma de trabalho diminui signi- 
ficativamente as clássicas divisões qualitativas do processo produtivo, típicas do trabalho fordista (Idem, p. 113). O trabalho não teria se tornado apenas "afetivo", no sentido de que "produz também sentimentos, afetos, paixões, redes e contatos sociais, ou seja, uma nova subjetividade; ele teria desenvolvido também um caráter altamente cooperativo e coletivo" (Kalyvas, 2003, p. 267). Com a transição para a economia da informação, as linhas de produção em série são substituídas por um modelo em rede, como modelo organizacional da produção. Isso torna a produção mais dependente de formas cooperativas de trabalho, que, por outro lado, não se apoiam necessariamente em contatos físicos entre trabalhadores. Seria essa a cadeia que formaria o sujeito político que poderia oferecer oposição e resistência à soberania imperial. $\mathrm{O}$ tornar-se comum do trabalho representa, segundo eles, "a condição biopolítica da multidão" (Hardt e Negri, 2004, p. 113).

Para Hardt e Negri, a multidão consiste, assim, em uma multiplicidade de elementos que não se dissolvem em uma única unidade (Idem, pp. 139-142). Embora suas partes não se tornem indiferenciadas, ela se baseia, contudo, em uma unidade de ação. A multidão seria a subjetividade que emerge desse processo dinâmico entre singularidade e comunidade: ela designa "um sujeito social ativo que age com base naquilo que as singularidades compartilham em comum" (Idem, p. 100).

A multidão torna-se, assim, a expressão de um poder constituinte absoluto que se apoia sobre a cooperação social e se reproduz por meio do trabalho vivo - biopolítico. "Na espontaneidade criativa e imediata do trabalho vivo, o poder constituinte encontra sua própria capacidade de inovação; na imediaticidade cooperativa do trabalho vivo, o poder constituinte encontra sua massificação criativa" (Negri, 1999, p. 32). Embora sua expressão seja uma ou outra vez apropriada e dirigida pelos desígnios soberanos do império, a multidão pode romper com esse domínio e liberar sua potência criativa. Uma vez que isso fosse realizado, ela se tornaria um poder constituinte absoluto capaz de superar as divisões entre as esferas pública e a privada: uma forma espontânea e autorregulada de domínio sem Estado.

\section{A distinção império/multidão como deslocamento semântico da "soberania popular"?}

Michael Hardt e Antonio Negri reivindicaram expressamente para sua obra o caráter de um manifesto comunista do século XXI, e talvez não seja necessário exigir de um "manifesto político" a precisão e a acuidade de análise que se deseja 
de uma obra científica com a intenção de explicar os mecanismos políticos e jurídicos de uma sociedade mundial supercomplexa. Manifestos são, de fato, um artefato semântico do sistema político, e não do sistema científico. Mas os diagnósticos e as afirmações dos autores vão muito além da agenda política. Eles se baseiam em observações que podem ser também observadas, seja do ponto de vista da teoria política, a fim de se testar sua plausibilidade diante das estruturas que observam, seja como forma de explicar seu significado, até mesmo como manifesto. Se nos propomos a observar, portanto, a plausibilidade sociológica da diferença entre império e multidão, pode ser aconselhável buscar onde estariam as suas possíveis limitações ou contribuições teóricas e empíricas para a descrição do sistema político global.

O Estado de bem-estar social (Wohlfahrtstaat) serviu como designação semântica, nos ditos Estados centrais (Neves, 2006, pp. 175-185), para um arranjo institucional que registrava na ordem político-jurídica o imperativo da inclusão social em todos os sistemas funcionais (Luhmann, 1981, pp. 48 e ss.). Essas exigências vis-à-vis o sistema político surgiam não apenas em consequência das expectativas normativas relacionadas com a gradativa extinção hierarquias pré-modernas, mas como resultado também de uma resposta do sistema jurídico à diferenciação funcional, sobretudo na forma de uma expansão dos direitos de cidadania, que levava, por sua vez, a uma crescente temporalização de biografias individuais (desenvolvimento de carreiras) (Luhmann, 1989, pp. 244-249). De fato, em quase todos os sistemas jurídicos nacionais da sociedade mundial viu-se algum tipo de positivação de direitos sociais ao lado daqueles direitos concebidos como direitos civis, de defesa contra a ordem política e de garantia de liberdade (Law e Versteeg, 2011; Brunkhorst, 2002, pp. 96-110).E, mesmo que esses direitos tenham encontrado graves limitações na sua realização - em especial, graças à persistente diferenciação hierárquica dos sistemas políticos da sociedade mundial em centro e periferia -, a realidade de que foram constitucionalizados simbolicamente (Neves, 1998, pp. 116-143) parece indicar que eles funcionam ao menos como uma espécie de expectativa contrafática bastante difundida na sociedade mundial moderna (Brunkhorst, 2002, p. 96).

A partir da perspectiva do sistema político, pode-se dizer que desse conjunto de estruturas complexas emergiu uma semântica particular. O conceito de soberania popular explicava o fato de o povo, como coletividade, não se deixar determinar de maneira última no sistema político moderno. Em vez disso, ele permanece como referência interna para a observação da contingência do próprio código poder. Nesse sentido, o povo - como artefato semântico 
e social - existiria apenas graças à constitucionalização política e por meio dos processos políticos juridificados que ela estabelece, os quais são apoiados pela dinâmica de positivação - também processual - de direitos individuais e sociais (Holmes, 2013, pp. 96-108). De acordo com Claude Lefort (1988, p. 18), poderíamos dizer que a "soberania popular" funcionaria como o símbolo do fato de que o "local do poder", à medida que é ocupado por processos temporalizados e abertos a novos resultados, permanece vazio.

Mas são justamente essas condições extremamente exigentes que parecem ser ameaçadas pelo crescente processo de transnacionalização econômica e jurídica da sociedade mundial: tanto os mecanismos de inclusão típicos do Estado de bem-estar, mesmo em sua forma simbólica, como a centralidade dos processos políticos nacionais, acoplados à produção de normas jurídicas por meio da forma constitucional, parecem ser gradativamente relativizados. Como vimos, diversas formas de produção de direito parecem concorrer com as formas produzidas constitucionalmente na sociedade mundial atual. Os novos arranjos de governança global, que favorecem o poder privado de organizações em detrimento da circulação democrática de poder político, parecem desestruturar a capacidade do sistema político em manter em operação seus processos diferenciados e garantir algum tipo de irritação sobre sistemas funcionais como a economia, a ciência e mesmo a educação globais (Crouch, 2004, pp. 31-53; Streeck, 2013, pp. 106-131; Brunkhorst, 2013). E a ordem que parece emergir dessa nova constelação pós-nacional em nada nos lembra uma ordem centralizada. Os regimes de governança transnacionais são, ao contrário, extremamente fragmentados (Koskenniemi, 2007; Picciotto, 2012, pp. 22-25), refletindo, aparentemente, as especificidades de distintos sistemas funcionais, que desenvolvem uma linguagem constitucional particular, com vistas a satisfazer suas próprias demandas por regulação (Teubner, 1996).

Se as condições estruturais de reprodução da política se alteram e a comunicação produzida pela política democrática perde o sentido que tinha, isso parece ter consequências para a semântica política, se a entendemos a partir da perspectiva de uma teoria dos sistemas. No contexto do sistema político moderno, marcado pelo conceito de democracia, deveríamos nos perguntar, então, se essas novas condições estruturais de reprodução não teriam repercussões tanto para o significado como para a plausibilidade da semântica da soberania popular. Em outras palavras, deveríamos nos perguntar quais são as possibilidades de politização de problemas sociais em uma sociedade mundial que se transnacionaliza e em que processos políticos baseados no Estado 
constitucional perdem peso na reprodução das operações basais do poder de decidir sobre a vida coletiva.

Entendo que é a essas questões que Hardt e Negri parecem procurar respostas. O seu manifesto dirigido a uma multidão global poderia ser, assim, descrito como uma resposta, no âmbito da reflexão, às transformações estruturais da forma de operação do sistema político mundial. Uma observação de seu esforço teórico deveria, porém, levar em conta em que medida tal manifesto se baseia em descrições acertadas do processo político mundial contemporâneo e não reflete apenas as aporias da política diante das pressóes advindas do processo de transnacionalização da sociedade mundial.

Se, sob a forma da política nacional, o protesto e o conflito podiam ser transformados em demandas políticas passíveis de serem processadas institucionalmente e serem retraduzidos, na linguagem do direito, como regulações que irritavam diversos setores da sociedade, em escala transnacional veem-se apenas movimentos dispersos de protesto, que dificilmente articulam pautas persistentes e estruturadas ou conseguem formar um equivalente funcional para a opinião pública nacional. $\mathrm{Na}$ esfera nacional, a soberania popular funcionava como símbolo semântico que descrevia a possibilidade estrutural de decisões coletivas serem politizadas e negociadas, tornando-se conflitivas e podendo levar a novas dinâmicas evolutivas em distintos sistemas. Essa possibilidade era atualizada por meio de garantias procedimentais inclusivas (sufrágio universal, igualdade política etc.) e processos juridicamente regulados, que permitiam uma certa visibilidade da indeterminação social da unidade do sistema político (do próprio povo): a política servia, assim, para descarregar as pressões e as incertezas socialmente dispersas acerca de problemas decisórios coletivos mediante processos de decisão contingentes (eleições, votações parlamentares, decisões constitucionais). Mas quais seriam os equivalentes funcionais transnacionais para os processos que deram origem a essa semântica ou para os direitos sociais que possibilitavam a inclusão de indivíduos como cidadãos capazes de se integrar nos processos políticos? Como se articulariam os conflitos e os protestos na ausência de um Estado que pudesse funcionar como endereço central das demandas sociais? Ora, na ausência das condições estruturais que deem suporte à semântica da soberania popular, talvez outras semânticas possam emergir para descrever os problemas e as respostas sociais relacionados a decisóes com impacto coletivo e que impliquem o exercício de poder social.

Uma tendência que poderia ser identificada, nesse processo de transição, seria a da emergência de semânticas baseadas em um crescente apelo a emoções moralizadas e a diferenças baseadas em simplificações totalizantes, que 
6. Anker se utiliza aqui do conceito de "melancolia de esquerda" (linke Melancolie) cunhado por Walter Benjamin (1972) em ensaio sobre o romance Fabian, de Erich Kästner, mas que ele dirigiu a outros radicais de esquerda do seu tempo, que segundo ele, ansiosos por reconhecimento, recorriam a uma emocionalização dramática da crítica social de esquerda como forma de autopromoção (Schuh, 2004). descrevessem a ordem global como uma oposição entre uma lógica total de dominação e possibilidades intangíveis e, em certo sentido, moralizadas de resistência. Semânticas com essas características corresponderiam a modelos de processos de politização no interior de sistemas de dominação em que não há mecanismos de procedimentalização das decisões, como ocorria nos sistemas políticos do absolutismo - em que a disputa de poder assumiria formas de vida ou morte, fortemente apoiadas em semânticas totalizantes. Elas se baseariam, sobretudo, em formas de moralização da disputa política, descrita, por exemplo, como uma guerra de todos contra todos ou como uma oposição mais ou menos radical baseada na diferenciação amigo/inimigo.

Compreendo que a diferença império/multidão poderia ser observada, de um ponto de vista sociológico, como um reflexo das transformaçóes do sistema político descritas. Mas a sua resposta (semântica), que também aspira a ser um manifesto de resposta a esses desafios, representaria muito mais uma exposição das aporias do sistema político contemporâneo do que uma semântica capaz de transformá-lo. Isso se refletiria, por exemplo, em como a descrição de Hardt e Negri procura unificar contextos políticos, econômicos e jurídicos extremamente complexos e fragmentados, estruturados em formas extremamente especializadas de regulação, em formas unitárias de diferenciação política, com base em uma única distinção: aquela entre império e multidão. Para os autores, o império seria uma ordem total e global que não deixaria espaços para oposições, senão na forma de uma mobilização total da multidão. Esta, por sua vez, seria composta de uma unidade política cujo processo de unificação não parece depender de nada senão de uma decisão político-moral correta. A ideia de uma unidade de todos os "trabalhadores", "pobres" e "humilhados do mundo" parece, porém, ignorar não apenas a diversidade e a multiplicidade de conflitos que existem entre a também fragmentária multidão, como também as causas dos processos de exclusão que os colocam em uma posição de marginalização social. Com efeito, se observamos os mecanismos de exclusão que reproduzem assimetrias globais, é bem evidente que esse tipo de oposição simplificada serve muito mais para tornar invisíveis as constelações complexas e diversas de causalidade que muitas vezes põem "pobres" contra "pobres", "trabalhadores" contra "trabalhadores", e também o império contra o próprio império.

É nesse sentido que Elisabeth Anker (2012, p. 146) identifica o que ela aponta como "melodrama de esquerda" (left melodrama) ${ }^{6}$, que seria típico da formulação de Hardt e Negri e de alguns outros autores que apelam para descrições semelhantes, baseadas em diferenças radicais - como Agamben, por exemplo. Segundo ela, esses autores substituiriam a análise social crítica 
por uma romantização quase literária dos diagnósticos políticos. Desse modo, mesmo como manifesto, o texto apresentaria claras limitações. A expressão "melodrama de esquerda" significaria, nesse contexto, que o discurso teórico é incapaz de produzir um diagnóstico consistente das condições políticas e sociais de um tempo, apelando então a mecanismos emocionais e morais para mobilizar mais os sentimentos do que a ação do leitor.

Se observamos o manifesto de Hardt e Negri como um fenômeno sociológico, cujo sentido pode ser reconstruído como resultado das condições políticas e sociais atuais, o caráter "melodramático" do manifesto poderia refletir exatamente a impotência das formas tradicionais de organização política e também da inadequação da semântica política típica do Estado nacional para refletir a complexidade das condições de reprodução da sociedade mundial de hoje. Seu caráter literário poderia indicar uma transição semântica da política, à qual corresponderia uma transição estrutural dos problemas relacionados com conflitos de interesse para um sistema político marcado por uma forte moralização e emocionalização, consequências de sua impotência diante da complexidade de sistemas funcionais que muito pouco se deixam irritar por suas pretensões de intervenção.

Ainda assim, é difícil imaginar como seria possível, com base em tal manifesto, estruturar e organizar qualquer tipo de ação política (Anker, 2012, p. 146). Como seria possível, por exemplo, qualquer tipo de revolução (ou reforma) sem formas de organização? Que estruturas responsáveis pelo governo da sociedade mundial deveriam ser modificadas? Quais os processos políticos e as formas de autoridade que deveriam ser revolucionadas? E, sobretudo: que tipo de revolução seria necessária em cada caso, em cada domínio funcional, em cada regime global de autoridade e governo? Seria uma mesma revolução na economia, na ciência, no esporte, na educação e na medicina, ou cada setor deveria exigir uma forma específica de transformação? A que custo se deixaria revolucionar a ciência, desde a política, sem que se ameaçasse a sua própria especificidade? Que processos deveriam ser utilizados para levar a cabo essas revoluções? Assim que nos fazemos essas perguntas, tornamos evidente quão importante é um diagnóstico adequado das condições de reprodução e exercício de poder na sociedade mundial. Uma tarefa que talvez seja mais relevante do que a construção de quaisquer manifestos. Afinal, se questões políticas são descritas na forma de uma luta do bem contra o mal, torna-se mais fácil uma tomada de posição: todos costumam preferir o lado do bem. Se nos perguntarmos, porém, o que seria o bem em uma sociedade mundial tão complexa, a resposta certamente dependerá de quem a observa. 


\section{Referências bibliográficas}

Adorno, Theodor \& Horkheimer, Max. (2000), Dialektik der Aufklärung. Frankfurt, Suhrkamp.

AmstutZ, Marc \& KaraVAS, Vaio. (2009), "Weltrecht: Ein Derridarisches Monster". In: CALliess, Gralf-Peter et al. (orgs). Soziologische Jurisprudenz, Festschrift für Gunther Teubner zum 65. Geburtstag. Berlim, De Gruyter.

Anker, Elisabeth. (2012), "Left melodrama". Contemporary Political Theory, 11 (2): $130-152$

BECK, Ulrich. (2009), Macht und Gegenmacht im globalen Zeitalter. Frankfurt, Suhrkamp. Benjamin, Walter. (1972), "Linke Melancholie: Zu Erich Kästners neuem Gedichtbuch”. In: Gesammelte Schriften III. Frankfurt, Suhrkamp.

BRUNKHORST, Hauke. (2000), "The enlightenment of rationality: remarks on Horkheimer's and Adorno's Dialectics of Enlightenment”. Constellations, 7 (1): 133-140.

BRUNKHORST, Hauke. (2002), Solidarität. Von der Bürgerfreundschaft zur globalen Rechtsgenossenschaft. Frankfurt, Suhrkamp. . (2009), "Machbarkeitsillusionen, feierliche Erklärungen und Gesänge: Zum Verhältnis von Evolution und Revolution im Recht". In: CALLIESs, Gralf-Peter et al. (orgs). Soziologische Jurisprudenz, Festschrift für Gunther Teubner zum 65. Geburtstag. Berlim, De Gruyter. . (2012), Legitimationskrisen: Verfassungsprobleme der Weltgesellschaft. Baden-Baden, Nomos.

Carrol, William \& Fenema, Meindert. (2002), "Is there a transnational business community?”. International Sociology, 17 (3): 393-419.

Crouch, Colin. (2004), Post-democracy. Cambridge, Polity. . (2011), The strange non-death of neoliberalism. Cambridge, Polity.

DJELIC, Marie Laure. (2006), "Marketization: from intellectual agenda to global policy-making”. In: DJELIC, Marie Laure \& SAHLIN-ANDERSON, Kerstin (orgs.). Transnational governance: institutional dynamics of regulation. Cambridge, Cambridge University Press.

DJelic, Marie Laure \& SAHLIn-Anderson, Kerstin. (2006), "Introduction - A world of governance: the rise of transnational regulation”. In: DJELIC, Marie Laure \& SAHLIN-ANDERSON, Kerstin (orgs.). Transnational governance: institutional dynamics of regulation. Cambridge, Cambridge University Press.

Drori, Gili \& MEYER, John W. (2006), “Scientization: making a world safe for organizing”. In: DJELIC, Marie Laure \& SAHLIN-ANDERSON, Kerstin (orgs.). Transnational governance: institutional dynamics of regulation. Cambridge, Cambridge University Press. 
FitzPATRICK, Peter. (2002), "Laws of empire". International Journal for the Semiotics of Law, 15: 253-271.

GOODALE, Mark. (2005), "Empires of law: discipline and resistance within the transnational system". Social \& Legal Studies, 14 (4): 553-583.

GRIMM, Dieter. (2001), “Die Bedingungen demokratischer Rechtssetzung”. In: GRIMM, Dieter \& Wingert, Lutz (orgs.). Die Öffentlichkeit der Vernunft und die Vernunft der Öffentlichkeit. Frankfurt, Suhrkamp.

HALL, Rodney B. \& BiERSTEKER, Thomas J. (2004), “The emergence of private authority in the international system". In: (orgs.). The emergence of private authority in global governance. Cambridge, Cambridge University Press.

HardT, Michael \& Negri, Antonio. (2001), Empire. Cambridge, MA, Harvard University Press.

. (2004), Multitude: war and and democracy in the age of empire. Nova York, Penguin.

Holmes, Pablo. (2013), Verfassungsevolution in der Weltgesellschaft: Differenzierungsprobleme des Rechts und der Politik im Zeitalter der Global Governance. Baden-Baden, Nomos.

Honneth, Axel. (1989), Kritik der Macht: Reflexionstufen einer kritischen Gesellschaftstheorie. Frankfurt, Suhrkamp.

JeSSOP, Bob. (1995), "The regulation approach, governance, and post-Fordism: alternative perspectives on economic and political change?". Economy and Society, 24 (3): 307-333

Kalyvas, Andreas. (2003), "Feet or clay? Reflections on Hardt's and Negri's Empire". Constellations, 10 (2): 264-279.

KANTOROwics, Ernst. (1997), “The king's two bodies: a study in medieval political teology". Princeton, NJ, Princeton University Press.

KASTNER, Fatima. (2007), "Luhmanns Souveränitätsparadox: Zum generativen Mechanismus des politischen Systems der Weltgesellschaft”. In: NEVEs, Marcelo \& VOIGT, Rüdiger (orgs.). Die Staaten der Weltgesellschaft. Niklas Luhmanns Staatsverständnis. Baden-Baden, Nomos.

Keohane, Robert O. (2002), "Governance in a partially globalized world". Power and governance in a partially globalized world. Nova York, Palvrage.

Koskenniemi, Martti. (2007), "The fate of international public law: between technicque and politics". The Modern Law Review, 70 (1): 1-30.

LEFORT, Claude. (1988), “The Question of Democracy”. In: Democracy and political theory. Cambridge, Cambridge University Press.

LINDAHL, Hans. (2010), "A-legality: postnationalism and the question of legal boundaries". The Modern Law Review, 73 (1): 30-56.

Luhmann, Niklas. (1980), "Gesellschaftsstruktur und semantische Tradition”. Gesells- 
chaftsstruktur und Semantik 1: Studien zur Wissenssoziologie der modernen Gesellschaft. Frankfurt, Suhrkamp. . (1981). Politische Theorie im Woblfahrtsstaat. Munique/Viena, Gunther Olzog. . (1989), "Individuum, Individualität, Individualismus". Gesellschaftsstruktur und Semantik: Studien zur Wissenssoziologie der modernen Gesellschaft, Bd. 3. Frankfurt, Suhrkamp.

. (1990), "Verfassung als evolutionäre Errungenschaft". Rechtshistorisches Journal, 9: 176-220. . (1993), Das Recht der Gesellschaft. Frankfurt, Suhrkamp. . (2000), Die Politik der Gesellschaft. Frankfurt, Suhrkamp. . (2004), "Sinn, Selbstreferenz und soziokulturelle Evolution". In: BURKART, G. \& RUnKeL, G. (orgs.). Luhmann und die Kulturtheorie. Frankfurt, Suhrkamp. Mieville, China. (2004), "The commodity-form theory of international law: an introduction“. Leiden Journal of International Law, 17: 271-302.

NEGRI, Antonio. (1999), Insurgencies, constituent power and the modern State. Minneapolis, University of Minnesota Press.

Neves, Marcelo. (1998), Symbolische Konstitutionalisierung. Berlim, Dunker \& Humblot. . (2006), Entre Tềmis e Leviatã. São Paulo, Martins Fontes.

NoelKe, Andreas. (2011), "Transnational economic order and national economic institutions: comparative capitalism meets international political economy”. Max-Planck-Institut für Gesellschaftsforschung (MPIfG) Working Paper. Disponível em mpi-fg-koeln.mpg.de, consultado em 18/4/2013.

PASHUKanis, Evgeny. (2002), The general theory of law and marxism. New Brunswick, NJ, Transaction Publishers.

PicciotTo, Sol. (1997), "Networks in international economic integration: fragmented States and the dilemmas of neo-liberalism". Northwestern Journal of International Law \& Business, 17 (2-3): 1014-1056.

RUGGIE, John G. (1998), "Globalization and the embedded liberalism compromise: the end of an era?” In: STREEK, Wolfgang (org.). Internationale Wirtschaft, nationale Demokratie: Herausforderungen für die Demokratietheorie. Frankfurt, Campus.

SAND, Inger-Johanne. (2009), "Hybrid law: law in a global society of differentiation and change". In: CALLIESS, Gralf-Peter et al. (orgs). Soziologische Jurisprudenz, Festschrift für Gunther Teubner zum 65. Geburtstag. Berlim, De Gruyter.

SCHARPF, Fritz. (1997), "Globalisierung als Beschränkung der Handlungsmöglichkeiten nationalstaatlicher Politik”. Max Planck Discussion Paper 97/1. Disponível em mpi-fg-koeln.mpg.de, consultado em 18/4/2013.

SCHUH, Franz. (2004), "Walter Benjamins Grausamkeit”. Disponível em http://www. zeit.de/2004/39/WalterBenjaminsGrausamkeit, consultado em 21/10/2014. 
STÄHELI, Urs. (2000), Sinnzusammenbrüche, Eine dekonstruktive Lektüre der Systemtheorie Luhmanns. Weilerswist, Velbrück.

STICHWEH, Rudolf. (2000a), "Systems theory as an alternative to action theory? The rise of communication as a theoretical option". Acta Sociologica, 43 (5): 5-13.

. (2000b), "Semantik und Sozialstruktur, Zur Logik einer systemtheoretischer Unterscheidung". Soziale Systeme, 6 (2): 237-250.

TeUbner, Gunther. (1987), “Juridification: concepts, aspects, limits, solutions". In: (org.). Juridification of social spheres: a comparative analysis in the areas of labor, corporate, antitrust and social welfare law. Berlim, De Gruyter. . (1996), "Globale Bukowina. Zur Emergenz eines transnationalen Rechtspluralismus”. Disponível em www.uni-frankfurt.de/fb/fb01/1_Personal /em_profs/ teubner/dokumente/Bukowina_english.pdf, consultado em 6/12/2012.

Vesting, Thomas. (2009), "Politische Verfassung? Der moderne (liberale) Verfassungsbegriff und seine systemtheoretische Rekonstruktion". In: CALLIESS, Gralf-Peter et al. (orgs). Soziologische Jurisprudenz, Festschrift für Gunther Teubner zum 65. Geburtstag. Berlim, De Gruyter.

Schmitт, Carl. (2004), Politische Theologie. Vier Kapitel zur Lehre von der Souveränität. Berlim, Duncker \& Humblot.

Tilly, Charles. (2004), Contention and democracy in Europe, 1650-2000. Cambridge, Cambridge University Press.

Walker, Neil. (2008), "Taking constitutionalism beyond the State". Political Studies, 56: 519-543.

WIENER, Jarrod. (1995), "The transnational political economy: a framework for analysis". Kent Papers in Politics and International Relations, 4 (11).

Willke, Helmut. (2001), Atopia: Studien zur atopischen Gesellschaft. Frankfurt, Suhrkamp.

. (2003), Heterotopia: Studien zur Krisis der Ordnung moderner Gesellschaften. Frankfurt, Suhrkamp. 


\section{Resumo}

Deslocamentos transnacionais da soberania popular: império e multidão como distinção pós-democrática?

No presente artigo, realizo uma reconstrução sociológica da semântica da soberania popular, relacionando-a, com base em uma abordagem de teoria dos sistemas, aos processos de diferenciação estrutural do sistema político moderno. Ao se apreciarem os processos de transnacionalização e a descrição proposta por Hardt e Negri, levanta-se a questão acerca de quais estruturas seriam descritas pelo par de conceitos império e multidão, e em que grau esses conceitos têm plausibilidade sociológica, seja como descrição adequada da política mundial pós-nacional, seja como suposto "manifesto democrático para o século XXI". Palavras-chave: Teoria dos Sistemas; Sistema político; Transnacionalização; Império; Pós-Democracia.

\section{Abstract}

Transnational dislocations of popular sovereignty: empire and multitude as post-democratic distinction?

In this paper I attempt to reconstruct the semantics of popular sovereignty from the perspective of systems theory, exploring its relation to the differentiation process between law and politics in modern society. After delineating the changing landscape of governance in the process of the transnationalization of power and law over recent decades, I turn to the concepts of Empire and Multitude proposed by Michael Hardt and Antonio Negri, attempting to make sense of them from a sociological standpoint. Ultimately the emerging semantics of Empire would appear to be symptomatic of structural changes in the political system of modern society.

Keywords: Systems theory; Political system; Transnationalization; Empire; Post-Democracy.

\footnotetext{
D OI: http://dx.doi.

org/10.1590/0103207020150113

Texto enviado em 18/11/2013 e aprovado em 12/12/2014.

Pablo Holmes é professor-adjunto de teoria política no Instituto de Ciência Política da Universidade de Brasília (Ipol/UnB), doutor em sociologia na Universidade de Flensburg, Alemanha. E-mail: pabloholmes@unb.br.
} 